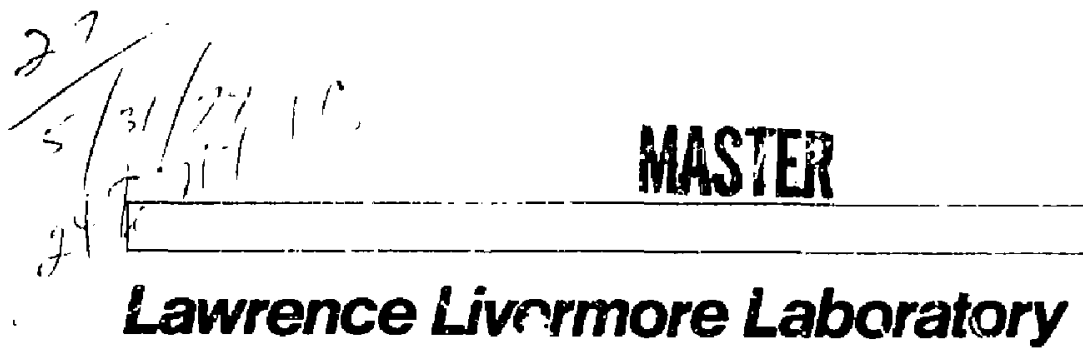

UCID- 18070

l

A COMPUTER MODEL FOR DUCTILE FRACTURE

B. Moran and J. E. Reaugh

May 6, 1979

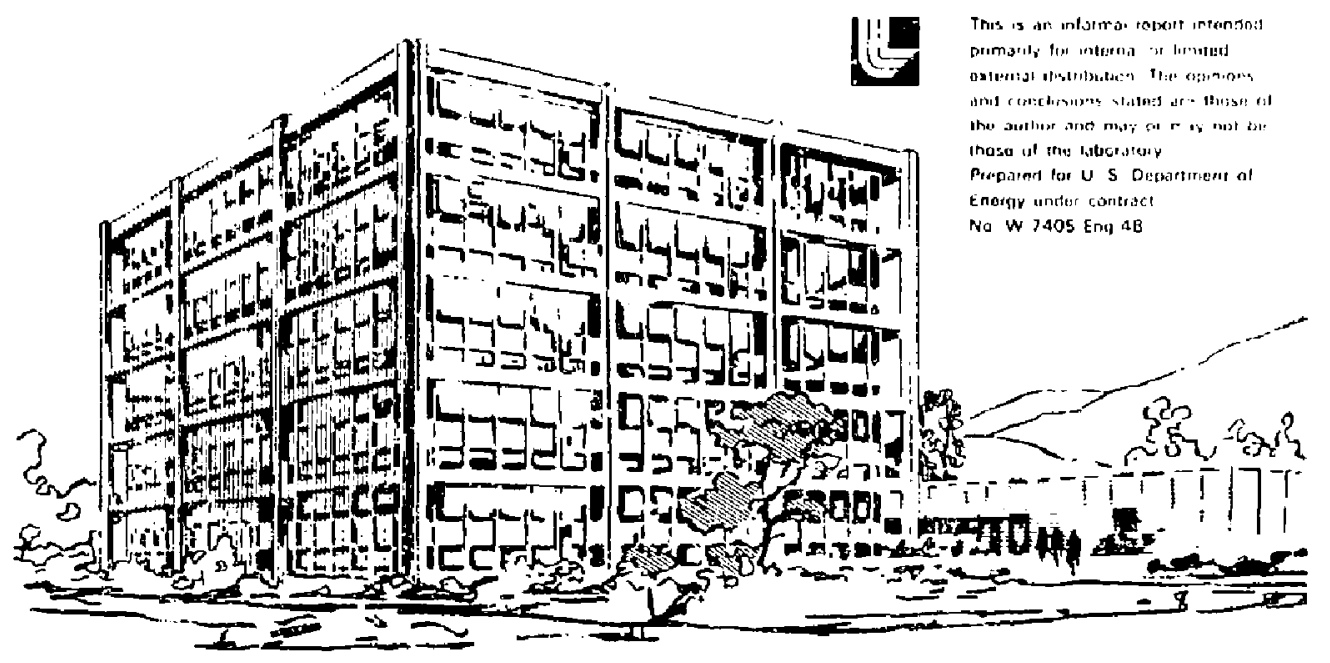


Alstract. . . . . . . . . . . . . . . . . . 1

Introduction. . . . . . . . . . . . . . . . . . 2

Project objectives. . . . . . . . . . . . . . . . . . . . 6

s'rategy. . . . . . . . . . . . . . . . . . . . 7

Accompl ishments . . . . . . . . . . . . . . . . . . . 9

Fracture Model calibration................. 9

simple Tension Specimens.................. . . 10

other Specimen Geometries. . . . . . . . . . . . . 11

Calibration Results. . . . . . . . . . . . . . . . . 11

Application of the Model to the Charpy V-Notch Test. . . . . . . . 12

Correlation of Charpy V-Noteh Data with Fracture Toughness . . . . . 13

Reconmer detione for Future Research . . . . . . . . . . . . . 16

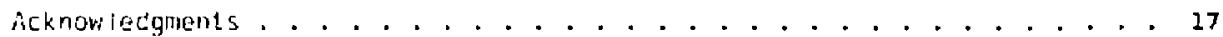

Refprences. . . . . . . . . . . . . . . . . . . . 18

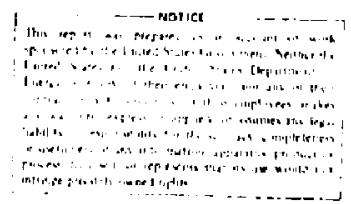




\section{A COMPUTER MODEL FOR DUCTILE FRACTURE}

\section{ABSTRAC;}

We describe a computer madel for predicting ductile fracture initiation and propagation. THe computer fracture model is calibrated by simple and notched round-bar tension tests and a precracked compact tension test. We use the model to predict fracture initiation and propagation in a Charpy specimen and compare the results with experiments. The calibrated model provides a correlation between Charpy $V$-notch (CVN) fracture energy and any measure of fracture toughness, such as $J_{1 c}$. We obtained a second simpler empirical correlation using the energy to initiate fracture in the Charpy specimen rather than total energy CVN, and compared the results with the empirical correlation of Rolfe and Novak. 


\section{INTRODUCTION}

The niargin of safety of nuclear reactor pressure vessels may be reduced by the embrittlement produced by neutron exposure. This margin of safety properly requires that the primary pressure-retaining boundary stays ductile while under stress, and the probability of rapidiy propagating fracture is negligible. The effect of neutron exposure, by Code of Federal Regulationl requirements, is determined from Charpy $V$-notch surveiliance specimens,

Charpy data from specimens broken at different temperatures show that energy to fracture increases dramatically over a relatively small temperature-transition range as the fracture mode changes from cleavage to ductile rupture. Irradiation may shift the fracture energy vs temperature curve to higher temperatures and reduce the upper-shelf iracture energy (see Fig. 1). The shift reduces the energy required for fracture in the transition region.

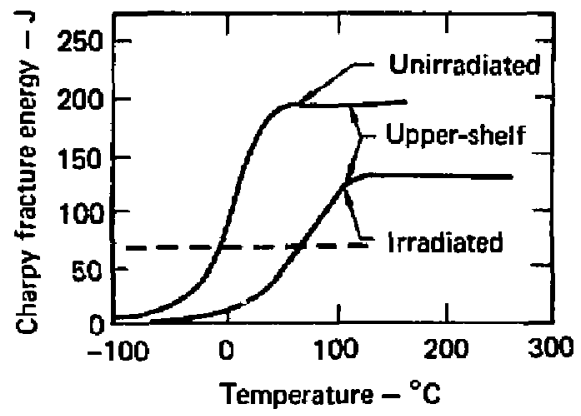

FIG. 1. Schematic diagram of Charpy fracture energy vs temperature for unirradiated and $i r-$ radiated stee 1 . The dashed line represents an energy of $67.8 \mathrm{~J}$. 
It is assumed ${ }^{1}$ that this shift also describes a corresponding temperature shift in the reference stress intenstty factor, $K_{\text {IR }}$ curve. ${ }^{2}$ This curve describes the lower bound to material fracture toughness and is used to limit the pressure during reactor heatup and cooldown. The shift is prescribed by law to be measured at. an energy of $67.8 \mathrm{~J}$. In some of the older reactors the upper-shelf Charpy tcughness levels may fall below $67.8 \mathrm{~J}$ and it is then impossible to determine the shift in the reference fracture toughness curve at this energy level.

It would seem to be more logical to use fracture toughness surveillance specimens directly to obtain the $K_{I R}$ temperature shift rather than to obtain it indirectly with Charpy spocimens. This turns out to be impractical because of the size and weiglit of the specimens required for fracture tougtiness data. The Charpy specimens are sniller, and the data are more easily obtained. The procedure is convenient and is thought to be conservative. The charpy test, developed in 1913, has a historical precedent that predates fracture mechanics.

This and other conservatisms built into reactor design, combined with the problem of radiation embr-ttlemeint, have threatened the unencumbered operation of some of the older pres'surized-water reactors. It is now necessary to understanu more piecisely the nature of ductile fracture and the margin of safety it has over design by linear-elastic fracture mechanics.

The project objective is to predict ductile fracture initiation, growth, and arrest in a reactor p.essure vessel by using a criterion for fracture initiation and an established computer program able to describe the detailed deformation states. 'This criterion is based on a combination of plastic strain and mean tensile stress acting over some material length. Material constants of the criterion are set by simulating laboratory tests of small specimens on the computer and adjusting the constants so the criterion predicts both crack initiation and growth in all geometries. The program is then applied to pressure-vessel calculations. The details of this work are reported by Norris et al. ${ }^{3}$ 
Our first phase concentrated on flat ductile fracture. He sought, a correlation between fracture toughness, which measures the resistance of material to the initiation of flat fracture from an initialiy sharp flaw, and the energy required to break a charpy $V$-notch specimen. This first phase has been completed. We established a toughness correlation using a computer model that predicts the initiation and propagation of ductile, flat fracture in computer simulations of a charpy $V$-notch test and a valid (according to ASTM proposed standards) fracture toughness lest. The model is based on the theory that ductile fracture is a process of microscopic void initiation, growth, and coalescence leading to macroscopil rupture. Fracture occurs when the product of plastic deformation and tensile mean stress exceers a critical value over a critical length. This critical length is characteristic of the size and distribution of the second-phase particles in the stee?.

Our madel contains adjustable parameters that are determined by comparing experiments--in which several different specimen geometries are pulled to fracture--with computer simulation of the experiments. We have calibrated the model for A533B-1 nuclear pressure vessel steel and for two states of increasing strength (and consequent embrittlement) attained by heat treatment. This embrittiement is not intended to simulate irradiated $A 533 \mathrm{~B}-1$ stee 1 , but to provide additional material states to test the fracture model. All our work was tone at $100^{\circ} \mathrm{C}$, an upper-shelf temperature for this $\mathrm{A533B-1}$ steel.

The calibrated model provides the 1 ink between Charpy initiation toughness and fracture toughness. A computer simulation of the Charpy $V$-notch specimen with the fracture model criteria provides the initiation energy. A calculation of the deformation of the compact tension specimen provides the state to calculate fracture toughness, $J_{I c}$, and hence the correlation is obtained. It is desirable to calibrate the fracture model using the surveillance specimens; we feel the simple tension specimen and the charpy specimens, contained in the reactor, may be sufficient. 
A second simpler empirical correlation between Cnarpy initiation energy and fracture toughness was also abtained. This correlation uses charpy initiation energy rather than the entire Charpy fracture energy. This improves correlations for steels using the total Charpy fracture energy and has a slightly improved quality over an earlier correlation by Rolfe and Novak. 7

As a by-product of the research, we performed detailed stress and strain analyses of five laboratory test specimens at failure: the simple tension specimen, two circumferentially notched tension specimens, the Charpy V-notch specimen, and the compact tension specimen.

The second phase of our work is under way. In this phase we plan to complete our model of ductila fracture by establishing the criteria for fracture in shear, and applying the completed model to the Charpy V-notch specimen and to a flawed pressure vessel. 


\section{PROJECT OBJECTIVES}

The goal of our research is to predict ductile fracture initiation, growth, and arrest in a reactor pressure vessel by using a criterion for fracture initiation and propagation and an established camputer program to describe the deformation phenomenon. Material constants of the criterion are set by simulating laboratory tests of small specimens on the computer, then adjusting the constants so the criterion predicts both crack initiation and growth in all geometries. The program will be applied to pressure-vessel calculations. The computer subroutines will then be included in the EPRI twoand three-dimensional STEALTH ${ }^{5}$ computer programs to make them available to utility and pressure vessel industry users.

As an intermediate step, we first sought to determine the correlation between upper-shelf Charpy $V$-notch energy and fracture toughness and to ascertain if the correlation was sat. ofactory for practical applications.

We now seek to complete the model of ductile fracture by estabilishing the criteria for fracture in shear. He wiil then use the completed model to predict ductile fracture in the Charpy $V$-notch specimen and in a flawed pressure vessel. 


\section{STRATEGY}

We use a phenomenological madel suggested by Wilkins ${ }^{6}$ and based on ductile-fracture theory. The model contains material-dependent parameters that we adjust by trial and error until we obtain a set of values that fits the experimentally determined fracture initiation data in several different geometries. The range of validity of the model is determined by the test data. It is important to note that because this is a phenomenological model rattier than a theory, the parameter vaTues cannot be identifled with specific physical properties. The form of the model has a strong empirical base, but is closely related to theories of ductile fracture.

A novel feature of our method is the use of computer-simulated experiments to obtain the detailed mechanical history of a material up to fracture initiation. Instead of detailed measurements (at microstructura) dimensions) of the stress and strain history, we use results from a computer simulation. Thus our method requires both experimental data on materials prior to fracture (so that we are sure the elastic-flastic behavior is well characterized) and the computer program and computer speed to make such detailed simulations feasible.

Our fundamental assumption is that the extension or the initiation of a crack can be treated as a constitutive property of materials. Fracture wiil then depend explicitly on the current mechanical state and past history of a local region, and will be independent of geometry and boundary conditions except as they affect the local state. Thus with our method, crack extension and crack initiation are treated alike. 
Our method requires a detailed stress analys is in the process $20 n e$. This approach to fracture differs from many others using characterizing parameters (such as the 3 -integral, ${ }^{7-9}$ crack-opening displacement, ${ }^{10}$ or strain-energy release rate.1, that might be used like the elastic stress-intensity factor. These methods neglect the details of the stress and deformation state in a process zone at the crack tip. A choice of these characterizing parameters, if they exist with appreciable yielding, is the goal of many other research programs. The work of Seaman et al. ${ }^{12}$ and Nemat-Nasser ${ }^{13}$ is similar to ours in that the details of the process zone are calculated, but their fracture process models the details of the material's microscopic void growth, which.we neglect and assume is more generally described by changes in macroscopic variables. McMeeking and Parks ${ }^{14}$ have done detailed largestrain calculations similar to ours, but their objective was to determine a range of test-specimen geometries such that the J-integrai characterizes the crack-tip stress and strain fields.

The calibrated modet can be used to do computer (rather than laboratory) experiments on specimen geometries that are acceptable for fracture resting, or the model can be used directiy for pressure-vessel fracture analysis. 


\section{I}

ACCOMPLISHMENTS

The four main accomplishments of the phase-one research were as follows:

- We obtained the three parameters required by our model for A533B-1 steel and for two additional heat-treatments of that material.

- With these parameters, our computer simulations signa! fracture initiation when each of five different spectmen geometries started to break.

- In addition, when we used the model to propagate flat fracture in the charpy $V$-notch test, wh also reproduced results of incicrupted tests.

- He developed a simple correlation between the energy required to break Charpy $V$-notch specimens ard the fricture toughness.

FRACTURE MODEL CALIBRATIO::

Following Wilkins, ${ }^{6}$ we chose the criterion for fracture to be

$$
D \geq D_{C}
$$

over at least a distance $r_{c}$, with

$$
D=\int_{0}^{-\bar{\varepsilon}} \frac{d \bar{\varepsilon}^{p}}{1-c \sigma_{m}} \text {, }
$$

Where $\vec{\varepsilon}^{P}$ is the equivalent piastic strain, $\sigma_{m}$ is the mean stress, and where the three model parameters are $D_{c}, r_{c}$, and $=$. We sought values of these parameters such that the model, in the computer simulation of a fracture test, correctly predicts fracture initiation and initial flat propagation. We found that the best correlations with experimental fracture data were obtained by considering each heat treatment as a unique material described by appropriate model parameters. With these calibrations we are able to predict 
Charpy fracture initiaiion in the three different material heats and track the initial flat fracture in the A533B-1 materiai. To calibrate the fracture mode1, we must know when and where fracture starts. This was determined from interrupted tests.

\section{Simple Tension Specimens}

The simple tension test provides the plastic-flow ?aw for the computer calculations and provides fracture inftiation data. Experimental fracture data provide information to calibrate the fiacture model. Calcularion of the severe necking that takes place in this specimen is a good test of the computer sof tware.

We performed computer simulations of the simple tension specimen, using the iteration technique discussed in Ref. 15, to obtain the plastic-flow law for the three steels. The work hardening for the three steels was $f$ it to a ratio of polynomial functions amenable to computer calculation. These flow curves are shown in Fig. 2 .

For the smooth tension specimens, fracture generally starts on axis at the point of maximum plastic strain and maximum tension.

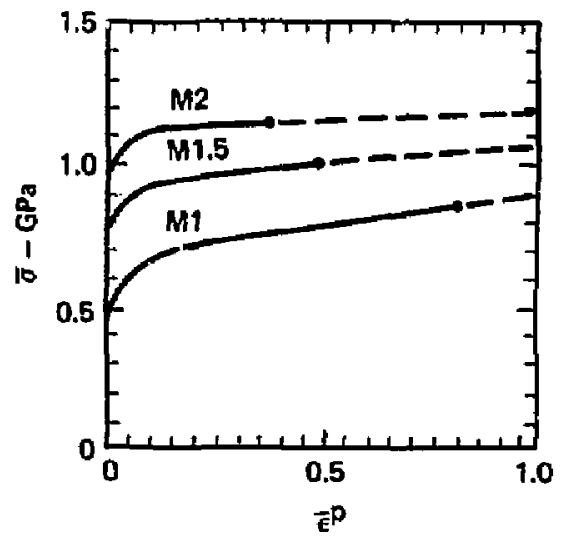

FIG. 2. Flow stress for A533B-1(M1) steel and the two additional heat treatments, $T=100^{\circ} \mathrm{C}$. 


\section{Other Specimen Geometries}

The notched tension specimens provide a differeilt multiaxial stress state and a larger hydrostatic tension (compared to the simple tension test) where fracture starts,

Fracture in the notched specimens usually occurred at the notch root where plastic strain is nighest, rather than at the location of maximum tension. Fracture started at or just before maximum load.

The precracked compact specimens are used to determine fracture toughness (as measured by $\mathrm{J}_{\mathrm{Ic}}$ ), and are also used to obtain constants of the fracture model and define the critica? dimension, $r_{c}$. They provide fracture data in the presence of the steep stress and strain gradients near an initially sharp crack.

\section{CALIBRATION RESULTS}

We obtained two different calibrations for each of the three heat treatments. The first calibration used the same $r_{c}$ value for each heat treatment (shown as set 1 in Table 1). The second calibration imposed leis constraint, and the best values of $c, D_{c}$, and $r_{c}$ were chosen (Set 2 of Table 1).

TABLE 1. Calibrated fracture model parameters.

\begin{tabular}{|c|c|c|c|c|c|c|}
\hline \multirow[b]{2}{*}{ Steel } & \multicolumn{3}{|c|}{ Set 1} & \multicolumn{3}{|c|}{ Set 2} \\
\hline & $c, \mathrm{GPa}^{-1}$ & $r_{c}, \mu m$ & $\mathrm{D}_{c}$ & c. $\mathrm{GPa}^{-1}$ & $r_{c}, \mu m$ & $\mathrm{D}_{\mathrm{c}}$ \\
\hline$A 533 B-1(M 1)$ & 0.70 & 25 & 1.1 & 0.70 & 25 & 1.1 \\
\hline MI.5 & 0.34 & 25 & 0.50 & 0.42 & 40 & 0.55 \\
\hline M2 & 0.45 & 25 & 0.53 & 0.40 & 15 & 0.50 \\
\hline
\end{tabular}

The quality of these calibrations can be estimated by observing the load-point displacement when critical damage, $D_{C}$, is obtained in the simulation, and to verify that it is within the uncertainty of the experimentally determined load-point displacement yalues. This is shown in Table 2. We conclude that the calibrations of Sets 1 and 2 are equally good. 
TABLE 2. Computed load-point displacement (LPO) at fracture.

\begin{tabular}{|c|c|c|c|c|}
\hline \multirow[b]{2}{*}{ Steel } & \multirow[b]{2}{*}{ Specimen } & \multirow{2}{*}{$\begin{array}{l}\text { Experiment al } \\
\text { LPD, mint }\end{array}$} & \multicolumn{2}{|c|}{ Computed LPD, $\mathrm{mm}$} \\
\hline & & & Set 1 & Set 1 \\
\hline \multirow[t]{4}{*}{ A533B-1(MI) } & 13-mm smooth & $10.90 \pm 0.40$ & 10.68 & 10.68 \\
\hline & 13-rm notched & $1.05 \pm 0.25$ & 0.98 & 0.98 \\
\hline & $27-m$ natched & $1.08 \pm 0.12$ & 1.02 & 1.02 \\
\hline & Compact & 0.89 & 1.04 & 1.04 \\
\hline \multirow[t]{4}{*}{$M 1.5$} & 13-mm snrooth & $6.90 \pm 0.30$ & 5.64 & 6.74 \\
\hline & 13-mm notched & $0.32 \pm 0.01$ & 0.39 & 0.42 \\
\hline & 27-mm notched & $0.37 \pm 0.03$ & 0.38 & 0.41 \\
\hline & Compact & 0.89 & 0.86 & 0.87 \\
\hline \multirow[t]{4}{*}{ M2 } & 13-rm smaoth & $5.40 \pm 0.30$ & 5.72 & 5.60 \\
\hline & $13-\mathrm{mm}$ notched & $0.37 \pm 0.02$ & $1) .37$ & 0.37 \\
\hline & $27-\mathrm{mm}$ notched & $0.38 \pm 0.02$ & 0.37 & 0.36 \\
\hline & Compact & 0.63 & 0.63 & 0.68 \\
\hline
\end{tabular}

APPLICATION OF THE MODEL TO THE CHARPY V-NOTCH TEST

We did interrupted tests on charpy specimens from the three steels. These tests were performed both dynamically, with stops to limit stritier travel, and quasi-statically. For these tests, initiation was determined by heat tinting the bent specimens, chilling in liquid nitrogen, breaking the specimens, and examining the fracture surfaces for crack initiation in the heat-tinted region.

We then used the model to initiate and propagate a fracture in a calculation of the A533B-1 Charpy specimen. We started a Charpy V-notch simulation in plane strain, initiated a fracture at the notch root with this model, and propagated the fracture for $0.8 \mathrm{~mm}$. We then compared results of 
this simulation with results from static and dynamic interrupted tests on Charpy specimens. The accumulation of internal energy in the Charpy specimen as a function of crack extension is shown in Fig. 3 with data from interrupted tests.

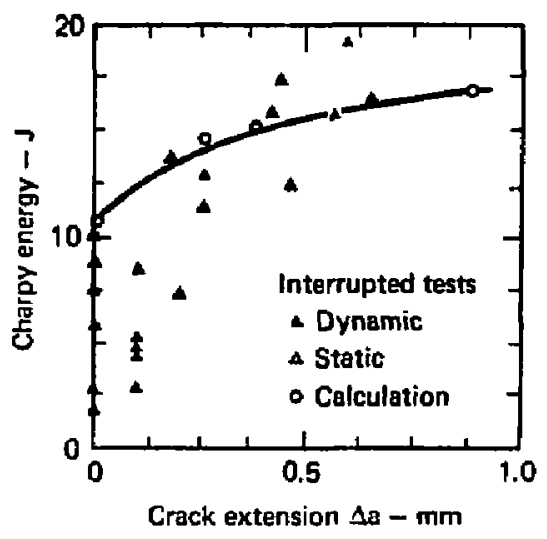

FIG. 3. Charpy specimen internal energy as a function of crack length for A533B-1.

CORRFLATION OF CHARPY V-NOTCH DATA WITH FRACTURE TOUGHNESS

We observed in our computer simulations of the Charpy test that at fracture initiation for A533B-1 steel the energy in the Charpy specimen is only $10 \%$ of the total energy required to break the specimen. Much of the energy required to fracture the specimen is dissipated in the shear lips that subsequently form in this ductile steel.

Our correlation between the Charpy energy and fracture toughness is not

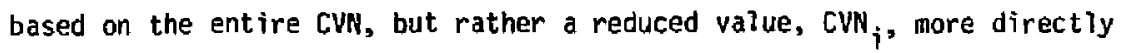
connected with fracture initiation. $\mathrm{CVN}_{j}$ may be obtained experimentaliy or 
by use of the calibrated fracture model. We also suggest a relationship between $C_{1}$ /CVN and the material yield stress based on the data from our three steels in the interrupted Charpy tests. We assume that this ratio is a universal function of yield stress. This is, perhaps, an oversimplified view and needs further verification.

The improvement in the correlation when only initiation energy is used can be seen by comparing Fig. 4, where fracture toughness vs CVN is shown for our data and data from Ref. 4 anci 16 , and Fig. 5 where the same fracture toughness data is shown as a function of our estimate of $\mathrm{CVN}_{\mathrm{i}}$.

When all data are considered, the rms fractional error of $\mathrm{J}_{\mathrm{IC}}=1.97$ $\mathrm{kN} / \mathrm{lm}$ CVN is $29 \%$. The Rolfe-Novak correlation has an rms fractional error of $28 \%$, and the rms fractional error of $J_{I C}=15.1 \mathrm{kN} / \mathrm{Jm} \mathrm{CVN}_{j}$ is $25 \%$.

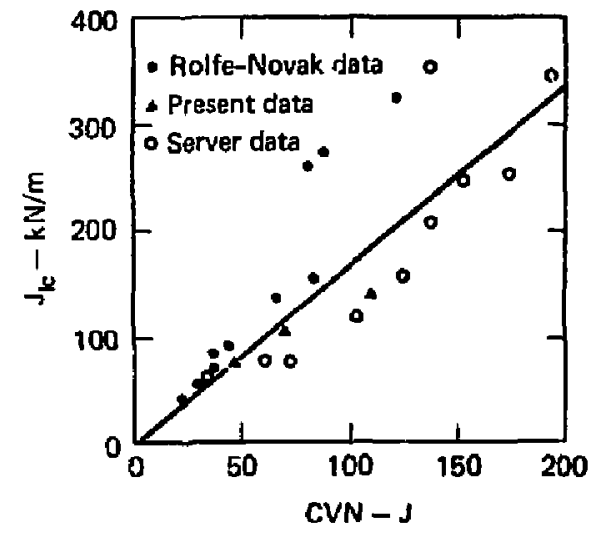

FIG. 4. Experimental fracture toughness vs dynamic Charpy energy. The straight line minimizes the mean fractional error.

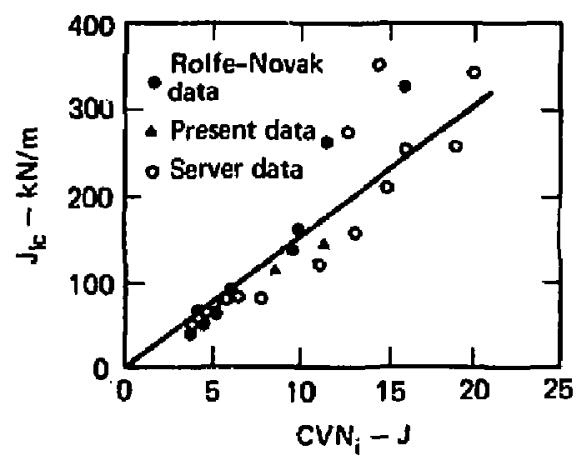

FIG. 5. Experimental fracture toughness us Charpy initiation energy. The straight iine minimizes the mean fraction.1? error. 
We conclude that a correlation to obtain fracture toughness, $\mathrm{J}_{\mathrm{I} C}$, from Charpy V-notch energy, CVN, may be obtained by considering only a portion of CVN absorbed by the specimen up to the time of initiation, $\mathrm{CVN}_{i}$. We present a method ${ }^{3}$ of extracting CUN $_{j}$ from interrupted, slow-bend tests of the Charpy specimen. We further demonstrate that the ratio $\mathrm{CVN}_{i} / \mathrm{CUN}$ is a slowly varying funcition of yield strength for our three heat treatments. By assuming this ratio to be a universal function of yield stress, we are able to correlate our data with data from materials with lower fracture toughness extremely well, and with data from materials with high fracture toughness fairly well. 


\section{RECOMMENDATIONS FOR FUTURE RESEARCH}

The current research phase is to extend the calibration testing to a torsion geometry where shear strain is the controlling fracture mechanism. This work would address the shear-lip formation that characterizes the later stages of ductile rupture. Our propagation wark, reported here, has only considered flat fracture where the nade-release technique is $\$$ at isfactory. A more general representation of fracture as described by Wilkins will be required to model shear tips.

After successful completion of this preliminary Charpy surveillance research, the methodology should be applied to irradiated and control group specimens so that the applicability of the methodology to irradiated steels can be evaluated.

The model should next be applied directly to vessel structures. The calculations reported here are all for sm، 'l laboratory specimens. Structures larger than our laboratory specimens still require the same zone size near the crack tip because the crack thickness and second-phase material particle distribution are the same size. A calculation of one of the Heavy-Section Steel Technology ${ }^{17}$ tests appears appropriate.

If the method proves successfur, it can be used to design new calibration specimens that are easier to calculate, and engineering structures that take full advantage of material ductility. 


\section{ACKNOWLEDGMENTS}

We are pleased to acknowledge the support of the Electric Power Research Institute, and the helpful discussions with Douglas Norris, David Quinones, and Mark Wilkins, all of Lawrence Livermore Laboratory. 


\section{REFERENCES}

1. Code of Federal Regulations, Title 10 (Atomic Energy), Part 50, "Licensing of Production and Utilization Facilities, Appendix G" (1973).

2. ASME Boiler and Pressure Vessel Cude, Section III, Appendix G, Protection Against Nonductile Failure, p. 492.

3. D. M. Norris, Jr., J. E. Reaugh, B. Moran, and D. F. Quinones, Computer Model for Ductile Fracture; Applications to the Charpy V-Notch Test, Electric Power Research Institute, Rept. NP-961, Research Project 603, Phase One Report, January 1979.

4. S. T. Rolfe and S. R. Novak, "Slow Bend $K_{I C}$ Testing of Medium-Strength High-Toughness Steels," in Review of Developments in Plane Strain Fracture Toughness Testing, ASTM STP 436, W. F. Brown, Jr., Ed., Philadelphia, PA, 1970, pp. 124-147.

5. R. Hofmann, STEALTH, A Lagrange Explicit Finite-Difference Code for Solids, Structural, and Thermohydraulic Analysis, Electric Power Research Institute, Palo Alto, CA, Rept. Np-260 (1976), vol. 1-4.

6. M. L. Wilkins, "Fracture Studies with Fwo- and Three-Dimensional Computer Simulation Programs," in Fracture Mechanics and Technology, Proc. Intern. Conf, on Fracture Mechanics and Technology, Hong Kong, March 1977, vol. 2 (Noordoff Int. Pub., Leyden, The NetherTands, 1977). Also same title as Lawrence Livermore Laboratory Rept. UCRL-78376 (1977).

7. R. J. Rice. Elastic-Plastic Fracture Mechanics, Technical Rept. No. 47, Material Research Laboratory, Brown University (July 1976). 
8. J. H. Hutchinson and P. C. Paris, "Stability Anaiysis of J-Controlled Crack Growth", ASTM Symp. on Elastic-Plastic Fracture, Atianta, Georgia, November 1977 (to appear in ASTM STP).

9. P. C. Paris, H. Tada, A. Zahoor, and H. Ernst, The Theory of Instability of the Tearing Mode of Elastic-Plastic Crack Growth, U. S. NRC Rept. NUREG-0311 (1977); also presented at ASTM Symp. Elastic-Plastic Fracture, At lanta, Georgia. (1977).

10. A. A. Wells, "Application of Fracture Mechanics At and Beyond General Yielding," in British Helding Journal, November 1963, pp. 563-570.

11. A. P. Kfouri and K. J. Milier, "Crack Separation Energy Rates in ElasticPlastic Fracture Mechanics," in Proc. Institution of Mech. Erg., London, 1976.

12. L. Seaman, D. R. Curan, and D. A. Shockey, "Computational Models for Ducti Te and Brittle Fracture," in J. Appl. Phys. 47, Nov. 1976, pp. 4814-4826.

13. L. Nemat-Nasser, "Overview of the Basic Progress in Ductile Fracture," in Trans. Intern. Conf. Structural Mechanics in Reactor Technology, 4th San Francisco, CA 1977, pp. L2/1-11.

14. R. M. McMeeking and D. M. Parks, "On Criteria for J-Dominance of Crack-Tip Fields in Large Scale Vielding," ASTM E-24 Symp. on Elastic-Plastic Fracture, Atlanta, GA, November 1977.

15. D. M. Norris Jr., B. Moran, J. K. Scudder, and D. F. Quinones, "A Computer Simulation of the Tension Test," in $\underline{\mathrm{J}}$. Mech. Phys. Solids, 26, 1 (1978). 
16. W. L. Server, "Stat ic and Dynamic Fibre Initiation Toughness Results for Nine Pressure Vessel Materials," presented at the ASTM Symp. on ElasticPlastic Fracture in Atlanta, GA in November, $19: 7$.

17. J. G. Merk Te. G. D. Whitman, and R. H. Bryan, An Evaluation of the HSST Program Intermediate Pressure Vessel Tests in Terms of Light-WaterReactor Pressure Vessel Safety, Oak Ridge National L aboratory Rept., ORNL-TM-5090 (1975). 